\title{
Reconstructive And Conservative Surgery by Tubal Implantation in Mullerian Anomalies - A Case Report
}

\author{
Dr. Priyanka ${ }^{1}$, Dr. Singh Ranjeet ${ }^{2}$, Dr. Meena Kusumlata ${ }^{3}$, Dr. Meena B.S. ${ }^{4}$ \\ ${ }^{1}$ Obs And Gynae Department, Sms Medical College, Jaipur, India) \\ ${ }^{2}$ (Dnb Pediatrics, Jaipur, India) \\ ${ }^{3}$ Sr. Professor \& Unit Head Obs And Gynae Department, Sms Medical College, Jaipur, India) \\ ${ }^{4}$ Sr. Professor And Head Of The Department Obs And Gynae, Sms Medical College, Jaipur, India)
}

\begin{abstract}
Introduction: Congenital mullerian defects are more common than generally recognized and its prevalence among fertile/ infertile women vary from 3-4\%(1). Mullerian anomalies are associated with poor reproductive outcome.

Objective: To resume normal menstruation and reproduction by creation of normal anatomy in case of mullerian anomaly.

Case: Patient was presented with complaints of primary amenorrhea and infertility. Patient was diagnosed to have non communicating rudimentary horn with functioning uterus with vaginal agenesis.Surgery was done. Ovarian cyst and rudimentary horn was removed and then functioning tube of non-communicating horn was implanted over functioning uterus and a channel created to connect the uterine cavity with external environment. In follow up patient resulted in menstruation 1 month later.
\end{abstract}

Keywords : Conservative surgery, Mullerian anomalies, Reconstructive surgery, Tubal implantation

\section{Introduction}

Congenital abnormalities of the mullerian ducts are relatively common, occurring in $7-10 \%$ of all women and contributing to the problems of infertility, recurrent pregnancy losses and poor pregnancy outcomes that occur in approximately $25 \%$ of women with uterine anomalies. [1]Unicornuate uterus accounts for approximately 2.4-13\% of all müllerian anomalies.[2]The unicornuate uterus is caused by non-development of one mullerian duct. The condition usually is associated with various degrees of rudimentary horn connected to the unicornuate uterus when one of the ducts develops only partially. Various series, shows the rarity of such an anomaly, it has been reported to be of incidence of $0.06 \%$. Women affected by this disorder often have accompanying renal, skeletal and other anomalies.[3]Mullerian agenesis occurs in 1 out of every 4,000-10,000 females.[4]We report a case of unicornuate uterus with hematometra and hematosalpinx with noncommunicating rudimentary horn with non-functioning endometrium with cervical agenesis.

\section{Case Report}

A 23-year-old married nulliparous female presented with primary amenorrhea with cyclical abdominal pain for 3-4 days every month with history of vaginoplasty 2 yr back. Pain was relieved by oral analgesics. There were no bladder or bowel complains. Her general and systemic examinations were within normal limits. Examination per abdomen revealed two firm, well-defined, non-tender, non-compressible, and non-reducible mass, one measuring $8 \times 8 \mathrm{~cm}$ in left iliac fossa and second arising from pelvis.On per speculum examination lower one third of vagina was pink coloured and upper two third was keratinized dark coloured (grafted).On per vaginal examination a good vaginal length with upper end of vagina blind.A solid, mobile mass of $8 \times 8 \mathrm{~cm}$ in left side and other mass in suprapubic location deviated to right side equal to uterine size of 12-14 week.All routine examinations revealed no obvious abnormality. An ultrasound scan of pelvis and abdomen revealed hematometra with left ovarian cyst. Computed tomography scan showed multicystic left ovarian mass compressing the vagina with hematometra.

A diagnostic laparoscopy was performed that revealed a unicornuate uterus (left) 10-12 week with hematometra, left fallopian tubes was distended and bluish in color suggestive of hematosalpinx. Left ovary was enlarged forming chocolate cyst. Unicornuate uterus was connected with right rudimentary horn with thick band. Right tube was normal and right ovary was enlarged.Right sided tube and ovary were connected with rudimentary horn.

On laparotomy, findings of laproscopy were confirmed. Left unicornuate uterus with hematometra with left hematosalpinx with enlarged left ovary $(10 \times 12 \times 10)$ was found.Right fallopian tube was normal. Right ovary was enlarged $(5 \times 4 \times 3 \mathrm{~cm})$ looking like endometrioma. Cervix was absent and uterus was not communicating with vagina. 
Reconstructive and conservative surgery of genital tract was decided with following aims \& objectives-

- To canalize uterus with vagina for normal menstruation and fertility.

- To Preserve the Hormonal milieu of a woman.

- $\quad$ To preserve the vascularity of adnexa.

Surgery was done in following steps-

Left ovarian chocolate cystectomy $f / b$ right ovarian cystectomy $f / b$ resection of rudimentary horn $f / b$ drainage of hematometra $\mathrm{f} / \mathrm{b}$ implantation of the right tube over the cornual like thin part of right side of the unicornuate uterus $\mathrm{f} / \mathrm{b}$ round ligament implantation over lower part of unicornuate uterus $\mathrm{f} / \mathrm{b}$ communication of unicornuate uterus with vagina.

The patient had an uneventful postoperative recovery. Her stitches were removed on the $7^{\text {th }}$ postoperative day and she was allowed to go home the same day.

In follow up patient resulted in menstruation 1 month later.

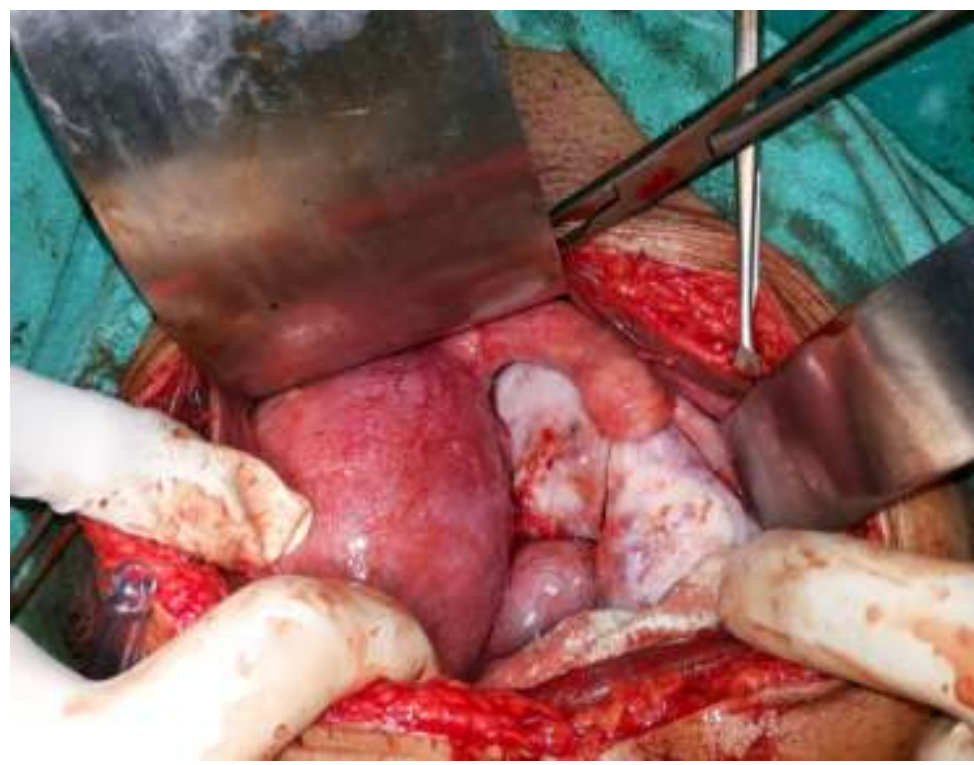

Fig. 1 Unicornuate Uterus With Rudimentary Horn With Bilateral Enlarged Ovaries

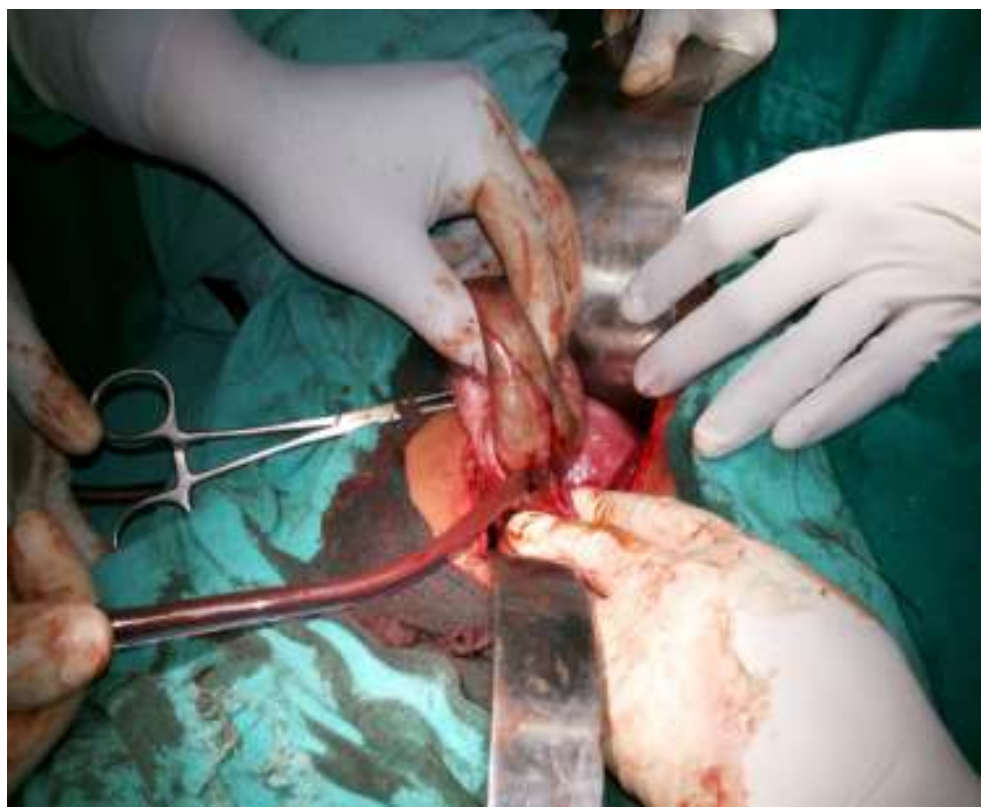

Fig. 2 Left Ovarian Chochalate Cystectomy 


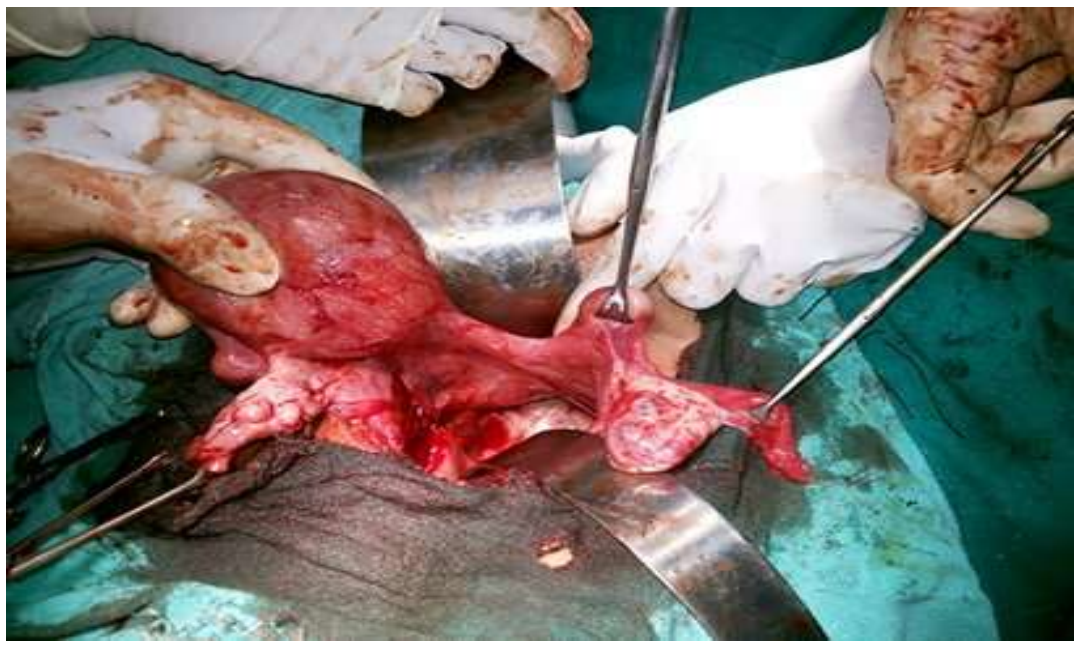

Fig 3 Left Unicornuate Uterus With Right Rudimentary Horn

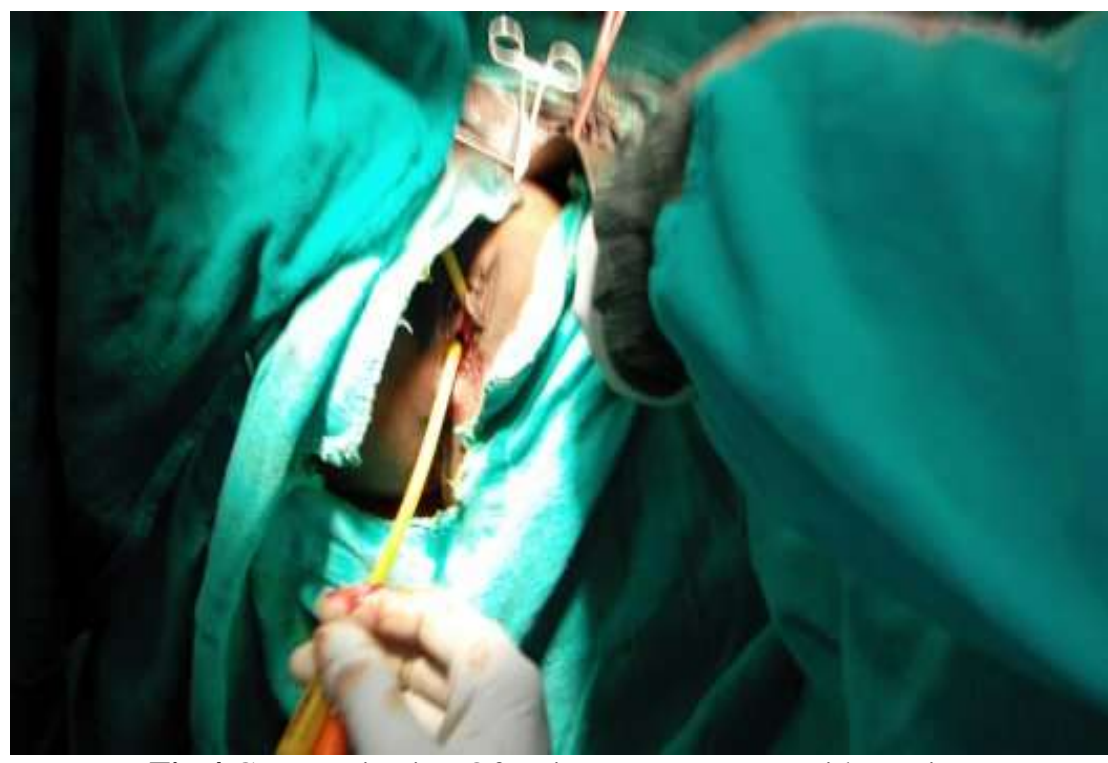

Fig 4 Communication Of Unicornuate Uterus With Vagina

American fertility society classification [5]

\section{Discussion}

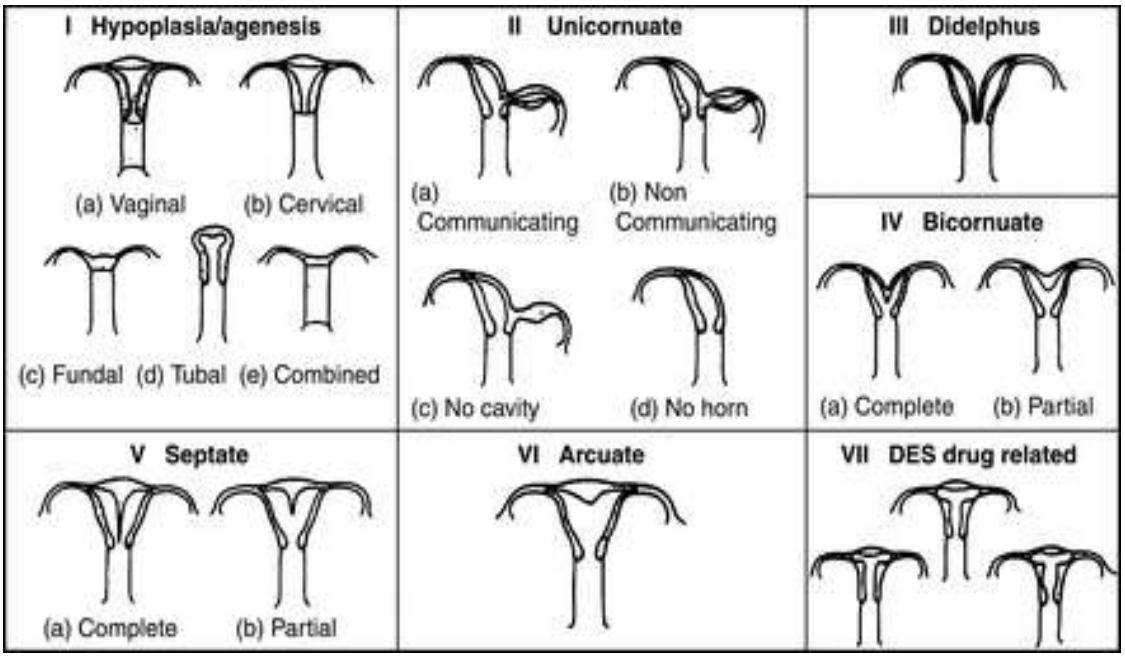


Rock JA proposed Modification of American Fertility Society classification of müllerian anomalies [6]:

Class I Dysgenesis of the müllerian ducts

Class II Disorders of vertical fusion of the müllerian ducts

1. Transverse vaginal septum

2. Obstructed

3. Unobstructed

4. Cervical agenesis or dysgenesis

Class III Disorders of lateral fusion of the müllerian ducts

1. Asymmetric-obstructed disorder of uterus or vagina usually associated with ipsilateral renal agenesis

a. Unicornuate uterus with a non-communicating rudimentary anlagen or horn

b. Unilateral obstruction of a cavity of a double uterus

c. Unilateral vaginal obstruction associated with double uterus

\section{Symmetric-nonobstructed}

a. Didelphic uterus

- Complete longitudinal vaginal septum

- Partial longitudinal vaginal septum

- No longitudinal vaginal septum

b. Septate uterus

- Complete

Complete longitudinal vaginal septum

Partial longitudinal vaginal septum

No longitudinal vaginal septum

-Partial

Complete longitudinal vaginal septum

Partial longitudinal vaginal septum

No longitudinal vaginal septum

\section{Bicornuate uterus}

- Complete

Complete longitudinal vaginal septum

Partial longitudinal vaginal septum

No longitudinal vaginal septum

-Partial

Complete longitudinal vaginal septum

Partial longitudinal vaginal septum

No longitudinal vaginal septum

\section{T-shaped uterine cavity (DES drug-related)}

\section{Unicornuate uterus}

- With a rudimentary horn

- With communicating endometrial cavity

-Without endometrial cavity

-Without rudimentary horn

Class IV Unusual configurations of vertical and lateral fusion defects.

\section{Embryology}

Complete development of a genital tract is dependent upon three stages, organogenesis, lateral and vertical fusions, and septal resorption. [8]Up to eight weeks of embryonic life, both mesonephric (Wolffian) and paramesonephric (Müllerian) ducts coexist. In the third month, one of the duct systems persists normally and the other regresses. [9] In a nine-week-old embryo, the Müllerian ducts first appear as invaginations of the dorsal coelomic epithelium. They penetrate the mesenchyme lateral to each Wolffian duct. [10] Two Müllerian ducts fuse to form the uterine canal and cervix at the tenth week of gestation. [9] The fused paramesonephric ducts form the epithelium and glands of the canal, and are covered by mesenchymal cells that comprise the muscles of the uterus and its peritoneum. [11] The solid tip of the paramesonephric ducts and urogenital sinus fuse at the end of the third month. Canalization of the uterine cavity, cervical canal and vagina is completed by the $22^{\text {nd }}$ 
week of pregnancy. The endometrium develops by the 20th week of pregnancy from the internal lining of fused Müllerian segments. [9] Vaginal fornices and the lower vagina differentiate from paramesonephric cells and the urogenital sinus, respectively.[8]

Therefore, we have concluded that the developmental problem in this case might have occurred between the 10th to 22nd weeks of pregnancy.

Mesonephric ducts are essential for normal Müllerian duct development. In both sexes the ureters develop from the mesonephric ducts. Abnormalities of the renal system and Müllerian ducts coexist. [9]

In this case, however there was no developmental abnormality in the urinary system. Thus it could be concluded that mesonephric duct migration and regression occurred normally.

Expression of specific genes is important for molecular development of specific structures. It has been suggested that the initial patterning is stabilized by fusion and a reciprocal interaction between the endoderm and mesoderm adjacent to the structure. Specific gene expression up regulates factors in the mesoderm that subsequently determine the type of structure that should be created.[8] The temporal pattern of gene expression, special relationships of developing tissues and cell-to-cell communications are important for normal structural development.[12] If fusion of the Müllerian system and the surrounding mesoderm had not occurred normally in a critical time period, canalization could be stopped in that special segment.[12] Complex anomalies have been described that do not exactly match AFS classifications and cannot be fully explained by the theory of embryologic development.[13,14] Generally atresia may occur due to lack of recanalization and is most likely the result of vascular accidents, which may be caused by malrotation. As a result, blood supply to that region is compromised, resulting in the lack of development of a segment [8], which could have been the probable etiologic factor in this case.

According to the American Fertility Society (AFS) a unicornuate uterus with rudimetary horn(non communicating with non- functioning endometrium) is classified as a class IIcof Müllerian anomaly. And cervical agenesis or dysgenesis is classified as a class IB Müllerian anomaly under segmental Müllerian agenesis-hypoplasia and class IIB in the classification of uterovaginal anomalies under disorders of vertical fusion. $[5,6]$ Agenesis of the uterine cervix is rare and usually associated with the absence of a segment or the entire vagina.[7]

The current case had a unicornuate uterus with rudimetary horn(non -communicating with nonfunctioning endometrium) that was obstructed at the lower segment, with absent cervix and no communication to vagina. This case might be considered a combination of unicornuate uterus with rudimentary horn and cervical dysgenesis; however, none of the available classifications completely matched her anatomical abnormality. The type of anomaly in our case_has been considered to be unusual according to the embryologic developmental theory of female reproductive tract anomalies.

We concluded that the developmental problem occurred between 10-22 weeks of gestation with 1 müllerian duct incompletely fails to elongate while the other develops normallyand defective lateral fusion of the malformed duct with contralateral ductand also a defect in segmental vertical fusion or canalization of the cervix. We theorize that probably the absence of an appropriate fusion in between the Müllerian ducts and with its underlying mesoderm, as well as loss of cell-to-cell communication and special gene expressions during a critical time period, or a vascular accident was responsible for this anomaly.

\section{Management}

Understanding the embryologic origin of the defect of mullerian anomalies is the key to its correct diagnosis. Clinical presentation: cyclical pain abdomen, amenorrhea etc. Diagnosis: pelvic / rectal examination, ultrasonography, hysterosalpingography, laparoscopy, hysteroscopy. MRI- it is the most accurate imaging method for diagnosis. Treatment: Hysterectomy has been recommended for patients with functional uteri and cervical agenesis or dysgenesis. However successful attempts in recanalization of the uterine cervix by laparotomy [15] or assisted by laparoscopy [16,17] have been reported. Despite the absence of normal cervical secretions in these cases successful pregnancies have been reported. [18]

\section{References}

[1]. Speroff L. The uterus. Mitchell C, ed. Clinical Gynecologic Endocrinology and Infertility. 8th ed. Philadelphia, Pa: Lippincott Williams \& Wilkins; 2005. 143.

[2]. Acién P. Incidence of Müllerian defects in fertile and infertile women. Hum Reprod. 1997 Jul. 12(7):1372-6.

[3]. Raga F, Bauset C, Remohi J, et al. Reproductive impact of congenital Mullerian anomalies. HumanReproduction 1997; 2277 : 2281-2312.

[4]. Evans TN, Poland ML, Boving RL. Vaginal malformations. Am J ObstetGynecol 1981;141:910-20.

[5]. The American Fertility Society classifications of adnexal adhesions, distal tubal occlusion, tubal occlusion secondary to tubal ligation, tubal pregnancies, müllerian anomalies and intrauterine adhesions. FertilSteril. 1988; 49: 944 - 955.

[6]. Rock JA: Surgery for anomalies of the müllerian ducts. In Thompson JD, Rock JA (eds): Telinde's Operative Gynecology, $7^{\text {th }}$ ed $p$ 688. Philadelphia, JB Lippincott, 1997) 
[7]. Buttram VC Jr., Gibbons WE. Müllerian anomalies: a proposed classication (An analysis of 144 cases). FertilSteril. 1979; 32 : 40 $-46$.

[8]. Sadler TW. Langmans Medical Embriology. 11th ed. Philadelphia: Lippincott Williams \& Wilkins; $2010: 89$ - 262.

[9]. Fritz MA, Speroff L. Clinical Gynecologic Endocrinology and Infertility. 8th ed. Philadelphia: Lippincott Williams \& Wilkins; 2011: $121-156$ and 341

[10]. Rock JA, Jones III HW. TeLinde's Operative Gynecology. 10th ed. Philadelphia: Lippincott Williams \& Wilkins; $2008: 539$ - 584.

[11]. Anderson JR, Genadry R. Anatomy and embryology. In: Berek JS, ed. Berek\& Novak's Gynecology. 14th ed. Philadelphia: Lippincott Williams \& Wilkins; 2007: 75 - 127.

[12]. Park SY, Jameson L. Minireview: transcriptional regulation of gonadal development and differentiation. Endocrinology. 2005; 146: $1035-1042$.

[13]. Vallerie AM, Breech LL. Update in Müllerian anomalies: diagnosis, management, and outcomes. Curr Opin Obstet Gynecol. 2010; 22: $381-387$.

[14]. Wright KN, Okpala O, Laufer MR. Obstructed uteri with a cervix and vagina. FertilStril. 2011; 95 : 290. e 17 - 19

[15]. Alborzi S, Momtahan M, Parsanezhad ME, Yazdani M. Successful treatment of cervical aplasia using a peritoneal graft. Int J Gynecol Obstet. 2005: 88: $299-302$

[16]. Fedele L, Bianchi S, Frontino G, Berlanda N, Montefusco S, Borruto F. Laparoscopically assisted uterovestibular anastomosis in patients with uterine cervix atresia and vaginal aplasia. FertilSteril. 2008; 89: 212 - 216.

[17]. Roberts CP, Rock JA. Surgical methods in the treatment of congenital anomalies of the uterine cervix. Curr Opin Obstet Gynecol. 2011; 23: $251-257$.

[18]. Deffarges JV, Haddad B, Musset R, Paniel BJ. Utero-vaginal anastomosis in women with uterine cervix atresia: long-term followup and reproductive performance. A study of 18 cases. Hum Reprod. 2001; 16: $1722-1725$. 